\title{
The state of ergonomics for mobile computing technology
}

\author{
Jack T. Dennerlein* \\ Department of Physical Therapy, Movement, and Rehabilitation Sciences, Bouvé College of Health Sciences, \\ Northeastern University, Boston, MA, USA
}

Received 3 March 2014

Accepted 30 April 2014

\begin{abstract}
.
BACKGROUND: Because mobile computing technologies, such as notebook computers, smart mobile phones, and tablet computers afford users many different configurations through their intended mobility, there is concern about their effects on musculoskeletal pain and a need for usage recommendations.

OBJECTIVE: Therefore the main goal of this paper to determine which best practices surrounding the use of mobile computing devices can be gleaned from current field and laboratory studies of mobile computing devices.

METHODS: An expert review was completed.

RESULTS: Field studies have documented various user configurations, which often include non-neutral postures, that users adopt when using mobile technology, along with some evidence suggesting that longer duration of use is associated with more discomfort. It is therefore prudent for users to take advantage of their mobility and not get stuck in any given posture for too long. The use of accessories such as appropriate cases or riser stands, as well as external keyboards and pointing devices, can also improve postures and comfort.
\end{abstract}

CONCLUSIONS: Overall, the state of ergonomics for mobile technology is a work in progress and there are more research questions to be addressed.

Keywords: Posture, wrist posture, injury, occupation, mobile phones, texting

\section{Introduction}

Since the introduction of the notebook computer, mobile computing technology has become a ubiquitous part of daily living and work (Fig. 1). In recent years mobile computers have dominated sales and deliveries. In 2008, sales of notebook or laptop computers exceeded sales of desktop computers, occupying about

\footnotetext{
*Address for correspondence: Jack T. Dennerlein, Department of Physical Therapy, Movement, and Rehabilitation Sciences, Bouvé College of Health Sciences, Northeastern University, Robinson Hall 308F, 336 Huntington Ave., Boston, MA 02115, USA. Tel.: +1 617 373 5428; E-mail: j.dennerlein@neu.edu.
}

$55 \%$ of the market [1], and in 2012, the market share of notebooks relative to desktops was comparable at $58 \%$. However, recent market analysis predicts that shipments of tablet computers will exceed shipments of notebook computers for 2013 and both notebook and desktop computers in 2015, with some 332 million tablets estimated to be shipped worldwide in 2015 [2]. Similarly, mobile phone sales for 2013 are expected to exceed 1.8 billion worldwide with smartphones surpassing 1 billion, approximately $55 \%$ of the mobile phone market [3].

As these technologies are introduced into the workplace and elsewhere there is concern about the health 


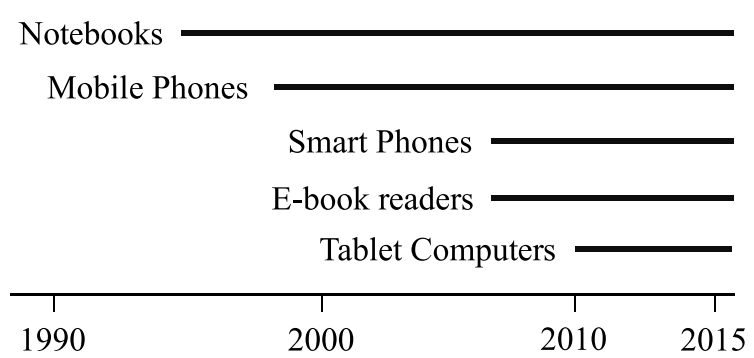

Fig. 1. General timeline of mobile computing technology during the past 20 years. Tablet computer are expected to out sell notebook computers in 2013.

implications of mobile computing devices, specifically in terms of ergonomic efforts to prevent chronic musculoskeletal health outcomes associated with overuse. In the late 1980s and 1990s as desktop computing became common in the office work environment, numerous studies reported associations between increases in work-related computer use and increases in adverse musculoskeletal health outcomes [4-7]. As a result ergonomists created usage guidelines for desktop computing, often referred to as use of Video Display Terminals (VDTs), with the goal of reducing the adverse musculoskeletal outcomes [8,9]. Mobile computing technology, however, affords users through their intended mobility many different work environments that increase the opportunity for users to adopt postures and configurations outside of those described in these guidelines [10]. As a result, there is concern that these non-standard postures and configurations may increase the risk of adverse outcomes.

In addition to affording a greater number of postures and configurations, mobile technology, via its smaller form factor and touch screen interfaces, allows for new physical interactions for computing, including utilizing the thumb for tapping and typing and the utilization of gesture inputs such as swipe, pan, and rotate. The effects of these new interactions on musculoskeletal health are unknown and as a result concern exists about these new interactions introduced by mobile computing.
Unlike desktop computing, the literature is sparse on documenting adverse musculoskeletal health outcomes with the use of mobile computing, especially for the working populations. Most of the studies examining health effects of notebook computers examine student or young adult populations reporting a slight increase, but not statistically significant prevalence, of musculoskeletal pain and symptoms for female notebook users [11-13] and an increase in prevalence in men who use portable computers during leisure time [14]. For mobile phone use and texting there are several case studies in the literature (e.g. Ming et al. [15] and Storr et al. [16]) with a single epidemiology study reporting association between duration of use and pain at the base of the thumb, at the shoulder, and at the neck [17].

There are other studies, mostly laboratory based, examining the effects of mobile technology on biomechanical parameters. These studies describe the load on tissues believed to be on the causal pathway between the computing technology and adverse musculoskeletal outcomes as described in ecological injury models of computer work related musculoskeletal disorders (Fig. 2) [18-20]. These laboratory studies provide insight into potential injury mechanisms and can guide practitioners in defining concerns and in turn best practices approaches for prevention.

Therefore, the main goal of this paper was to take a step in the direction of developing best practices surrounding the use of mobile computing devices that could be gleaned from the current field and laboratory studies of these mobile technologies.

\section{Approach/methods}

The overall approach to initiate the development of these best practices was to complete an expert review of studies related to mobile technology use that explored questions concerning musculoskeletal and biomechanical strain associated with using mobile computing technology. Being expert in nature, this review focused

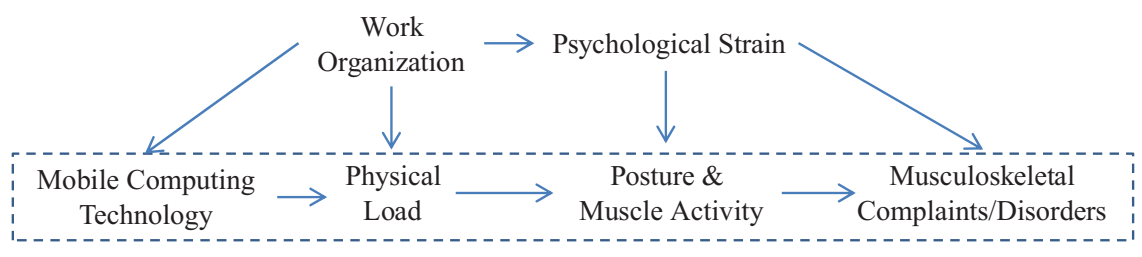

Fig. 2. The conceptual model that relates mobile computing technology to worker health outcomes adapted from ecological models of Sauter and Swanson (1996) [18] and Wahlstrom (2005) [19] The dashed box refers to the domain of this review. 
on mostly peer-reviewed literature found via PubMed or Google Scholar. The review was a simple search, and was by no means comprehensive or systematic.

Studies included in this review were both observational as well as experimental in nature and met specific criteria. The study had to examine mobile computing technology, which for the purposes of this study, consisted of three main types of devices: notebook/laptop computers, mobile or smart phones, and modern tablet computers. In addition the study had to include biomechanical/ergonomic outcomes such as posture, force, EMG, pain/comfort/discomfort, and/or motor performance Additionally studies examined factors in adult populations including college aged young adults.

Overall findings from these studies were simply presented in a narrative format organized by the three major device types. Within each type of device, findings were grouped based on the various regions of the upper extremities, for example the head/neck, the shoulder, the wrists, and the fingers and thumbs. When data from multiple studies with the same outcome measures were available, data were tabulated; however, that only existed for the notebook computers.

\section{Results}

\subsection{Notebook computing}

Due to their mobility notebook computers are used in a variety of work environments resulting in several user postural configurations. Findings in one study indicate that users often sit in chairs and work with notebook computers set on non-adjustable work-surfaces without the use of external keyboards, pointing devices, or monitors [21]. In addition to placing the notebook in the lap, notebook users take on many other non-desk postures [22]. These include sitting cross-legged, laying prone (face down), and seated with feet raised and legs either straight or knees flexed approximately $90^{\circ}$. In Gold et al., several non-desk postures were associated with increased discomfort, especially the prone position that requires neck extension and compression on the elbows. Seated postures with sufficient back support are often more comfortable than the prone, with relaxed shoulders and more neutral postures. While the postures varied across these various configurations, once in a specific configuration there is very little variability in posture [22].

Working with notebook computers on top of a desk has been associated with greater head and neck flexion; however, it is often associated with less wrist extension (Table 1). Compared to working with a desktop or a notebook in a desktop configuration (raised monitor and external keyboard and mouse) head flexion is about 10 degrees more when using a notebook computer [23-25]. Working with notebook computers on the lap is associated with even more head and neck flexion [26, 27]. This can be attributed to the lower screen height of a notebook computer, which has been reported several times as a significant factor for head and neck discomfort $[28,29]$. These postures can be improved by raising the monitor height with lap desks, inclines, a riser, or external monitor $[23,26]$.

Table 1

Postural effects of using notebook computers compared to desktops

\begin{tabular}{|c|c|c|c|}
\hline Postural Metric & $\begin{array}{l}\text { Difference to } \\
\text { Desktop }^{1} \\
\end{array}$ & Reference(s) & Configuration \\
\hline $\begin{array}{l}\text { Head tilt } \\
\text { (forward/downward) }\end{array}$ & $\begin{array}{l}8^{\circ} \\
4^{\circ}\end{array}$ & $\begin{array}{l}\text { Asundi et al. [23] } \\
\text { Szeto et al. [52] }\end{array}$ & Notebook on desk \\
\hline $\begin{array}{l}\text { Head tilt } \\
\text { (forward/downward) }\end{array}$ & $14^{\circ}$ & Asundi et al. [26] & Notebook on lap \\
\hline Neck flexion & $\begin{array}{l}4^{\circ} \\
7^{\circ}\end{array}$ & $\begin{array}{l}\text { Asundi et al. [23] } \\
\text { Straker et al. [25] }\end{array}$ & Notebook on desk \\
\hline Shoulder internal rotation & $\begin{array}{l}33^{\circ} \\
12^{\circ}\end{array}$ & $\begin{array}{l}\text { Asundi et al. [23] } \\
\text { Sommerich et al. [24] }\end{array}$ & Notebook on desk \\
\hline Wrist extension & $\begin{array}{r}-8^{\circ} \\
-1^{\circ} \\
-11^{\circ}\end{array}$ & $\begin{array}{l}\text { Sommerich et al. [24] } \\
\text { Asundi et al. [26] } \\
\text { Rempel et al. [34] }\end{array}$ & Notebook on desk \\
\hline Wrist ulnar deviation & $\begin{array}{r}-8^{\circ} \\
3^{\circ} \\
1^{\circ}\end{array}$ & $\begin{array}{l}\text { Asundi et al. [26] } \\
\text { Rempel et al. [34] } \\
\text { Sommerich et al. [24] }\end{array}$ & Notebook on desk \\
\hline
\end{tabular}

\footnotetext{
${ }^{1}$ For the all the metrics except for internal rotation, a positive number indicates a less neutral posture for the notebook compared to the desktop
} where as a negative number indicates a more neutral posture. For shoulder internal rotation the positive numbers suggest a more neutral posture. 
The wrist postures associated with using a notebook are generally less extended then when using a desktop, which is probably related to use of the internal mouse, as well as the large area proximal to the keyboard that provides a raised palm support [24, 30, 31].

Shoulder posture associated with using a notebook computer is similar to that when using a desktop; however, shoulder internal rotation is greater when using a notebook $[23,24]$. Since the external mouse is often placed to the right of the keyboard it requires external rotation. The placement of the touch pad in the center of the notebook proximal to the keyboard is affiliated with the more neutral shoulder posture of internal rotation [32].

\subsubsection{Use of accessories improves head and neck postures and user experiences}

Laboratory studies demonstrate that the use of an external monitor or increasing the height of the notebook's monitor improves head and neck postures and improves comfort associated with the head and neck. This association between posture and head and neck angles has been described in the review of some 24 studies by Straker et al. [29].

There are some simple methods for increasing the monitor height of a notebook, such as the use of a 3ring binder, with the goal of keeping the slope of the keyboard minimal [23]. For larger inclines and risers, the angle of the keyboard and eventually the height of its center increases drastically, becoming uncomfortable due to increased wrist extension. Therefore, when using a notebook with a riser, recommendations suggest the use of an external keyboard and pointing device $[26,33]$.
The use of external keyboards and pointing devices is associated with lower levels of discomfort and better levels of productivity [24, 34]. Performance is often better with an external mouse compared to an internal touch pad; however, touch pads often outperform the isometric or mini joystick pointing devices [35, 36]. Recently, external keyboards have become quite thin, which in theory reduces wrist extension compared to conventional keyboards.

Two published field intervention studies have demonstrated small improvements in pain and discomfort for a set of students that used external devices, mainly monitors and risers for their notebook computer [37, 38]. In both of these studies, there were improvements in pain and discomfort among those who used a riser albeit the differences were often small and mitigated when controlled for other covariates.

\subsection{Mobile and smart phones}

Observational studies have documented the various postures and user configurations young adults have adopted when using smart phones and mobile phones for texting $[10,39]$. These studies observed that users can stand or sit while using such devices and often flex the neck and head to view the screen of the devices. In sitting postures users often seek out support for their back and the arm holding the device. These studies also report that when using forearm support (or elbow support) less neck and head flexion is observed and participants reported fewer neck and shoulder complaints. Their observations suggest different postures exist between genders and between those with and without musculoskeletal pain.
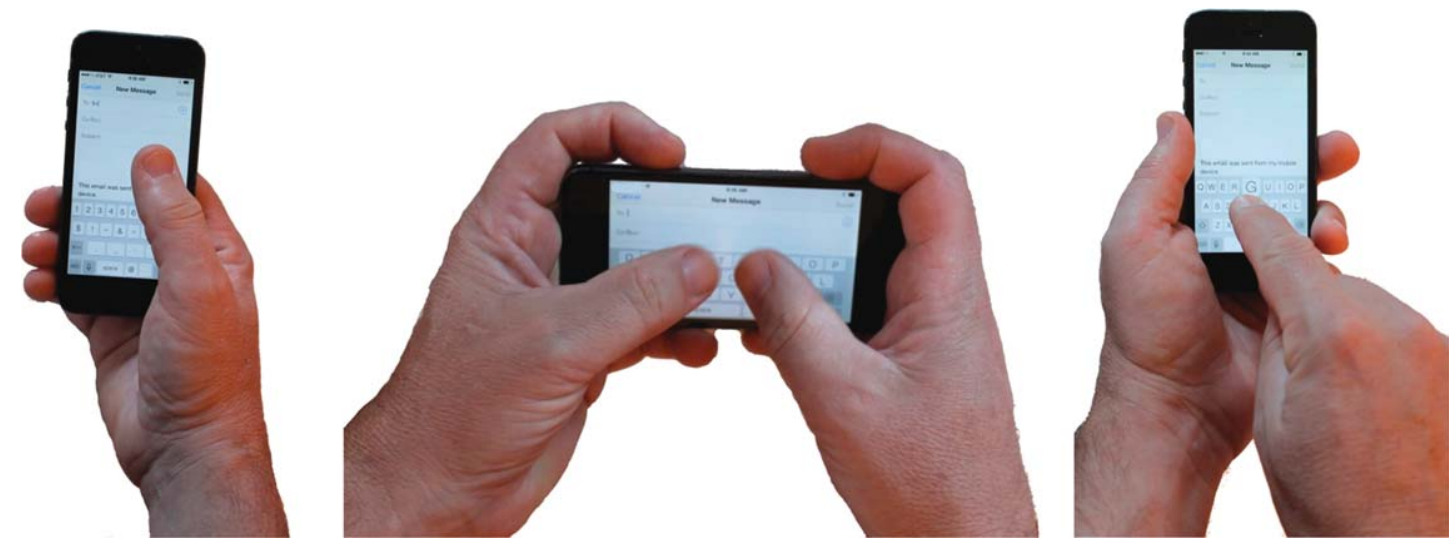

Fig. 3. The three most observed texting styles observed with approximately $95 \%$ observations being either the single handed (left) and the two handed with thumbs (middle) Gold et al. (2012) [10]. 

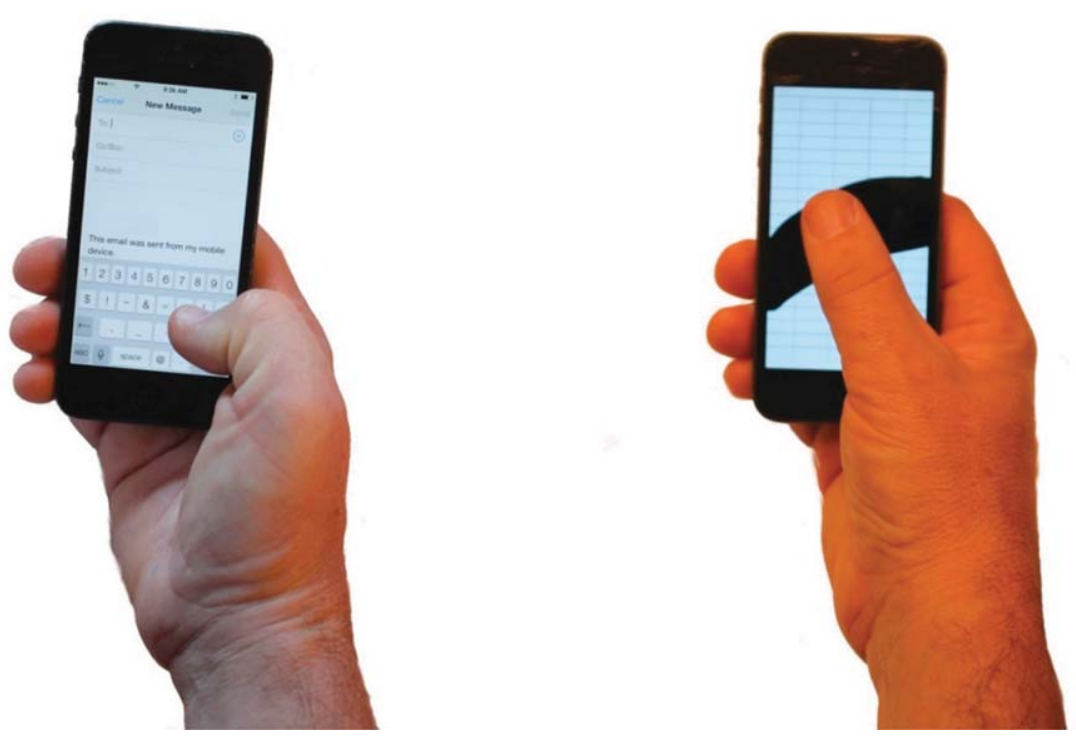

Fig. 4. When icons and buttons are located near the base of the thumb the thumb takes on a non-neutral posture (left photo) whereas when icons and buttons are placed along an arc as noted by the black area in the figure on the right the thumb posture takes on a more neutral posture. The phone on the right is displaying an image of the optimal area for thumb reach as described by Otten et al. [46]

These studies have also observed three fundamental techniques for entering text into phones (Fig. 3). Single handed and two-handed use, which utilize the thumb, accounted for approximately $95 \%$ of all observations, [10] while using one hand to hold and the index finger to activate keys and icons was observed only $2 \%$ of the time.

Since the thumb has been observed as a primary interaction digit, several studies have examined the posture and motor performance of the thumb (Fig. 4). These studies demonstrated that the thumb often obtains nonneutral postures close to the limits of its joints' range of motion, associated with poor motor performance [40-45]. The thumb performed best when the postures were most neutral, such as with abduction and adduction of the thumb swiping over the surface of the phone similar to a windshield wiper $[44,45]$. These high performance areas correspond to the comfortable thumb reach envelopes described by Otten et al. [46].

The literature suggests that motor performance of the thumb in activating keys and icons is also related to the size of the mobile phone $[41,44,47]$. Overall, smaller phones tend to have better performance in terms of speed and accuracy of reaching keys and icons on the surface. Other postures have not been investigated during mobile phone use.

A single observational epidemiological study has demonstrated associates between self-reported use of hand held mobile devices and pain at the base of the thumb, at the shoulder and at the neck [17]. Specifically Berolo et al. documents associations between time spent browsing the Internet and pain at the base of the right thumb and associations between total time using the device and pain in the neck and shoulder.

\subsection{Tablet computers and e-book readers}

Similar to notebook computers and mobile/smart phones, use of tablet computers has been associated with head and neck flexion. The experimental conditions of Young et al. [48] document the postures associated with four observed typical seated user configurations. Head and neck posture was the most flexed when placing the tablet in the lap, about $15^{\circ}$ more than neutral, similar to the $14^{\circ}$ observed for notebook computers (Table 1). While in the lap, holding the tablet with a hand or using a case that increases the tilt angle, the viewing angle approaches $90^{\circ}$ slightly improving head and neck postures. Moving the tablet onto a table improves the gaze and improves the head and neck angle, approaching a neutral posture. Overall, using cases for tablets and/or placing them on surfaces higher than the lap can assist in improving head and neck angles.

Use of tablets also creates a lot of non-neutral wrist postures depending on the specific user configuration [49]. When holding the device with one hand and using the other to interact with the touch-screen, the holding 

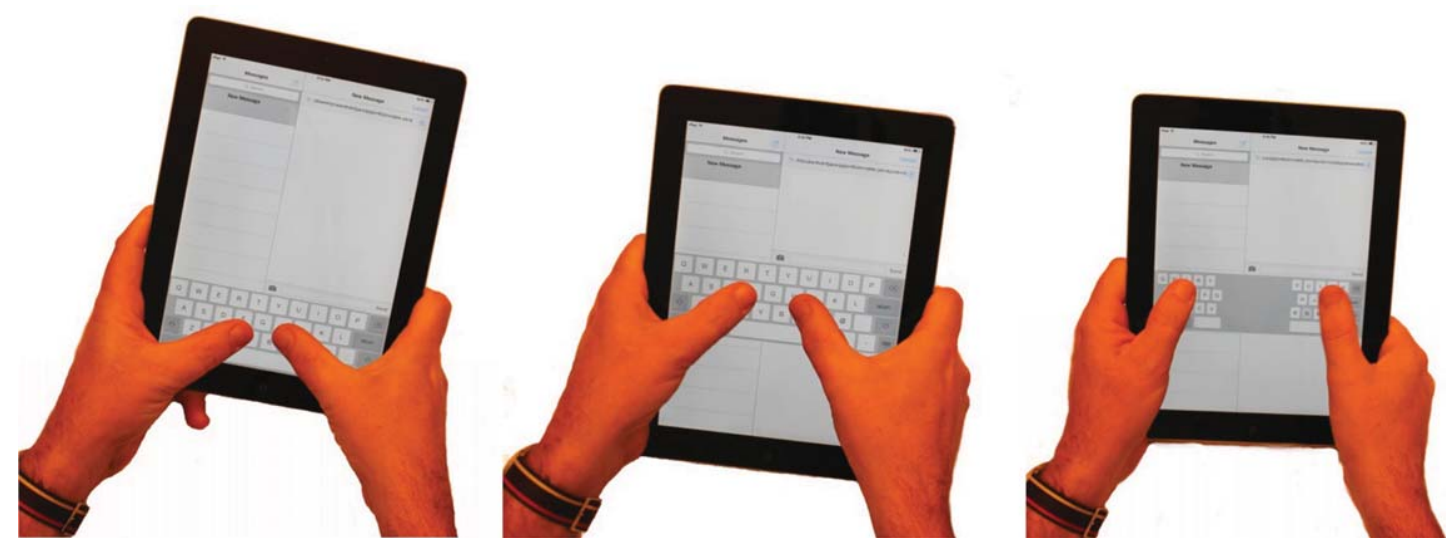

Fig. 5. Using two hands to operate a tablet to type on the keyboard is often associated with wrist extension, wrist ulnar deviation, and extension of the thumb joints. Moving the keyboard up into the middle of the tablet (middle) and using the split keyboard function (right) improves postures and comfort.

hand has a great deal of radial deviation, approximately $12^{\circ}$. Wrist extension was observed to be high during typing tasks, with median values reaching $40^{\circ}$ of extension [49]. Unlike typing on computer keyboards, wrist extension was not affected by the high variation in tilt angles of the tablet devices and the soft keyboards. Young et al. conjectured that users extend their wrists in order to view the keys displayed on the touch screen to ensure accurate typing.

Similar to mobile phones, users can use their thumbs to interact with the touch screen of tablets while holding the device with both the left and right hands; however, the larger screen of the tablet creates more non-neutral postures for both the thumb and the wrist [43]. These non-neutral postures can be reduced by moving the keyboard up on the screen and by using split keyboards (Fig. 5).

Pereira et al. [50] examined various tablet form factors while holding the tablet with the left hand only. When used while standing, for example during walk through inspections of construction sites or entering data into an electronic medical record system in a patient's room, it is expected that the device will be held with the left hand only. For this configuration, Pereira et al. concluded that smaller to medium size tablets are better in terms of usability, comfort, fatigue, and biomechanics [50].

\subsection{Accessories for tablet computers}

Overall the literature suggests that many of these issues can be mitigated with the use of accessories. Using a case that can stand without a user holding the tablet reduces the load on the hand and decreases forearm muscle activity [49]. In addition tablets with a rubberized back surface or a ledge type of handle were also easier to hold up with a single hand. Finally, the use of an external mechanical keyboard increases typing productivity, user comfort and shoulder muscle activity [51].

\section{Discussion and recommendations}

The main goal of this paper was to complete an expert review of the literature examining musculoskeletal comfort and biomechanical strain associated with the use of mobile computing technology, specifically notebook computers, smart mobile phones and tablet computers. Overall there were few field studies in the published literature that evaluated relationships between device usage, design and both biomechanical and comfort outcomes; however, there were several laboratory studies that examined the effects of various user configurations, device form factors, and device accessories on usability, comfort, and biomechanical strain.

The field studies for the most part document the various user configurations and hence often non-neutral postures that users adopt when using mobile technology, along with some evidence that longer duration of use is associated with more discomfort. From these observations it is prudent to recommend that users take advantage of the mobility of these devices in order to avoid usage in non-neutral postures for long periods of time. No specific time limit is known; however, if users feel discomfort after a period of time, they should take a break and adopt alternate postures and user configurations when use continues. 
For the notebook computers, many of the studies demonstrate that accessories can improve non-neutral postures associated with the devices. For any substantial duration, these studies support general guidelines of setting up a notebook to emulate a desktop computer, documenting postures closer to neutral, especially for the head and neck, with the use of accessories such as external monitors (and/or a notebook riser), keyboards and pointing devices. For the keyboard, thinner keyboards and larger mice promote more neutral hand and wrist postures. Small improvements can be obtained without these accessories by using other types of accessories such as a lapdesk designed to raise the computer monitor when on the lap or small inclines to raise the back of the notebook when placed on a desk.

Accessories for tablet computers and smart phones can also improve non-neutral postures. Cases can support and orient the devices for better viewing angles, improving neck and head postures while allowing for hands free operation unrestricting the posture of wrist and arms associated with holding the device. Based on the extreme wrist postures observed during typing on the devices, it is suspected that a thin external keyboard, such as many of the Bluetooth keyboards that work with both smartphones and tablets, will improve wrist postures and comfort.

When the devices are being held without support with a single hand or with two hands with the thumbs interacting with the touch surface, smaller and lighter devices appear to provide more comfort and usability. The lighter e-readers are often easier to hold without support compared to larger first generation tablet computers. The smaller phones often make it easier for the thumbs to reach much of the operating range of the touch screen, improving performance. Split keyboards on larger tablet computer can minimize over extension of the thumb and wrists. In addition, moving active icons from the bottom of the device nearest the base of the thumb also improves performance. Of course, there is a tradeoff between weight and the size of the visual area of the devices and this tradeoff depends on the use, purpose and preference of the user.

This review did not include studies that examined the many other effects of these technologies on health and productivity. For example there are studies that have explored the use of these technologies to interact with medical patients, deliver intervention messages around health behaviors, and measure and provide feedback on specific lifestyle behavior. In addition, this review did not seek out conference proceedings. With any evolving technology, the first wave of studies is often presented at conferences; however, the quality of such studies varies greatly and the details documented in the abstracts are often too terse for good interpretation. Finally, there have yet to be studies investigating the effects of gesture, such as swiping, rotating, resizing, and panning. Hence, it is unclear how specific design factors such as form factor and accessories may affect the performance of gestures.

Overall, the state of ergonomics for mobile technology is a work in progress. There have been some key studies that help understand the impact of the portability of these devices has had postures and comfort. Other studies have demonstrated the effects of device design configuration and the use of accessories has on user posture and comfort. From these studies, some basic recommendations for practice can be gleaned. There are more research questions to be addressed including examining how health and productivity outcomes are affected by gesture, multiple-touch, and other new interaction modes, such as furniture specifically designed to improve the support and flexibility of this new technology.

\section{Acknowledgments}

The author acknowledges Tom Albin for his support in preparing this manuscript and Kristin Ironside for her help in preparing the manuscript.

\section{References}

[1] Mann J. Notebook sales exceed PC sales says IDC: TechSpot.com; 2008 [8 September 2013]. Available from: http://www.techspot.com/news/32269-notebook-salesexceed-pc-sales-says-idc.html.

[2] IDC. IDC Forecasts Worldwide Tablet Shipments to Surpass Portable PC Shipments in 2013, Total PC Shipments in 2015 San Mateo, CA: International Data Corporation (IDC); 2013 [cited 20138 September 2013]. Press Release]. Available from: http://www.idc.com/getdoc.jsp?containerId=prUS24129713

[3] IDC. Worldwide Mobile Phone Market Forecast to Grow $7.3 \%$ in 2013 Driven by 1 Billion Smartphone Shipments, According to IDC Framingham, MA: International Data Corporation (IDC); 2013 [updated 04 Sep 2013; cited 20138 September 2013]. Available from: http://www.idc.com/getdoc.jsp?containerId=prUS24302813

[4] Faucett J, Rempel D. VDT-related musculoskeletal symptoms: Interactions between work posture and psychosocial work factors. Am J Ind Med 1994;26(5):597-612. PubMed PMID: 7832208

[5] Sauter SL, Schleifer LM, Knutson SJ. Work posture, workstation design, and musculoskeletal discomfort in a VDT data entry task. Hum Factors 1991;33(2):151-67. PubMed PMID: 1860702. 
[6] Bergqvist U, Wolgast E, Nilsson B, Voss M. The influence of VDT work on musculoskeletal disorders. Ergonomics 1995;38(4):754-62. PubMed PMID: 7729402.

[7] Gerr F, Marcus M, Ensor C, Kleinbaum D, Cohen S, Edwards A, et al. A prospective study of computer users: I. Study design and incidence of musculoskeletal symptoms and disorders. Am J Ind Med 2002;41(4):221-35. PubMed PMID: 11920966.

[8] HFES-ANSI. Human Factors Engineering of Computer Workstations. Santa Monica, CA: Human Factors and Ergonomics Society; 2007.

[9] Occupational safety and health administration O. Working safely with video display terminals. Washington, D.C.: U.S. Department of Labor, Occupational Safety and Health Administration (OSHA), 19973092.

[10] Gold JE, Driban JB, Thomas N, Chakravarty T, Channell V, Komaroff E. Postures, typing strategies, and gender differences in mobile device usage: An observational study. Appl Ergon 2012;43(2):408-12. PubMed PMID: 21764031. Epub 2011/07/19. eng.

[11] Hamilton AG, Jacobs K, Orsmond G. The prevalence of computer-related musculoskeletal complaints in female college students. Work 2005;24(4):387-94. PubMed PMID: 15920314. Epub 2005/05/28. eng.

[12] Chang CH, Amick BC, 3rd, Menendez CC, Katz JN, Johnson PW, Robertson M, et al. Daily computer usage correlated with undergraduate students' musculoskeletal symptoms. Am J Ind Med 2007;50(6):481-8. PubMed PMID: 17450542. Epub 2007/04/24. eng.

[13] Briggs A, Straker L, Greig A. Upper quadrant postural changes of school children in response to interaction with different information technologies. Ergonomics 2004;47(7):790-819. PubMed PMID: 15204289. Epub 2004/06/19. eng.

[14] Korpinen L, Paakkonen R. Physical symptoms in young adults and their use of different computers and mobile phones. Int J Occup Saf Ergon 2011;17(4):361-71. PubMed PMID: 22152502. Epub 2011/12/14. eng.

[15] Ming Z, Pietikainen S, Hanninen O. Excessive texting in pathophysiology of first carpometacarpal joint arthritis. Pathophysiology 2006;13(4):269-70. PubMed PMID: 17049823. Epub 2006/10/20. eng.

[16] Storr EF, de Vere Beavis FO, Stringer MD. Texting tenosynovitis. N Z Med J. 2007;120(1267):U2868. PubMed PMID: 18157194. Epub 2007/12/25. eng.

[17] Berolo S, Wells RP, Amick BC, 3rd. Musculoskeletal symptoms among mobile hand-held device users and their relationship to device use: A preliminary study in a Canadian university population. Appl Ergon 2011;42(2):371-8. PubMed PMID: 20833387. Epub 2010/09/14. eng.

[18] Sauter S, Swanson N. An ecological model of musculoskeletal disorders in office work. In: Moon SD, Sauter S, editors. Beyond biomechanics: Psychosocial aspects of Musculoskeletal Disorders in Office Work. London: Taylor and Francis; 1996. pp. 3-22.

[19] Wahlstrom J.Ergonomics, musculoskeletal disorders and computer work. Occup Med (Lond) 2005;55(3):168-76. PubMed PMID: 15857896. Epub 2005/04/29. eng.

[20] Bruno Garza JL, Eijckelhof BH, Huysmans MA, Catalano PJ, Katz JN, Johnson PW, et al. The effect of over-commitment and reward on trapezius muscle activity and shoulder, head, neck, and torso postures during computer use in the field. Am J Ind Med 2013. PubMed PMID: 23818000. Epub 2013/07/03. Eng.

[21] Malinska M, Bugajska J, Kaminska J, Jedryka-Goral A. Analysis of conditions and organization of work of notebook computer users. Int J Occup Saf Ergon 2012;18(3):443-9. PubMed PMID: 22995141. Epub 2012/09/22. eng.

[22] Gold JE, Driban JB, Yingling VR, Komaroff E. Characterization of posture and comfort in laptop users in non-desk settings. Appl Ergon 2012;43(2):392-9. PubMed PMID: 21726854. Epub 2011/07/06. eng.

[23] Asundi K, Odell D, Luce A, Dennerlein JT. Changes in posture through the use of simple inclines with notebook computers placed on a standard desk. Appl Ergon 2012;43(2):400-7. PubMed PMID: 21774912. Epub 2011/07/22. eng.

[24] Sommerich C, Starr H, Smith CA, Shivers C. Effects of notebook computer configuration and task on user biomechanics, productivity, and comfort. International Journal of Industrial Ergonomics 2002;30(1):7-31.

[25] Straker L, Jones KJ, Miller J. A comparison of the postures assumed when using laptop computers and desktop computers. Appl Ergon 1997;28(4):263-8. PubMed PMID: 9414366. Epub 1997/08/01. eng.

[26] Asundi K, Odell D, Luce A, Dennerlein JT. Notebook computer use on a desk, lap and lap support: Effects on posture, performance and comfort. Ergonomics 2010;53(1):74-82. PubMed PMID: 20069483. Epub 2010/01/14. eng.

[27] Moffet H, Hagberg M, Hansson-Risberg E, Karlqvist L. Influence of laptop computer design and working position on physical exposure variables. Clin Biomech (Bristol, Avon) 2002;17(5):368-75. PubMed PMID: 12084541. Epub 2002/06/27. eng.

[28] Straker L, Pollock C, Burgess-Limerick R, Skoss R, Coleman $\mathrm{J}$. The impact of computer display height and desk design on muscle activity during information technology work by young adults. J Electromyogr Kinesiol 2008;18(4):606-17. PubMed PMID: 17329126. Epub 2007/03/03. eng.

[29] Straker L, Burgess-Limerick R, Pollock C, Murray K, Netto $\mathrm{K}$, Coleman J, et al. The impact of computer display height and desk design on 3D posture during information technology work by young adults. J Electromyogr Kinesiol 2008;18(2):336-49. PubMed PMID: 17188894. Epub 2006/12/26. eng.

[30] Onyebeke LC, Young JG, Trudeau MB, Dennerlein JT. Effects of forearm and palm supports on the upper extremity during computer mouse use. Appl Ergon 2013. PubMed PMID: 24054504. Epub 2013/09/24. Eng.

[31] Kotani K, Barrero LH, Lee DL, Dennerlein JT. Effect of horizontal position of the computer keyboard on upper extremity posture and muscular load during computer work. Ergonomics 2007;50(9):1419-32. PubMed PMID: 17654034. Epub 2007/07/27. eng.

[32] Dennerlein JT, Johnson PW. Changes in upper extremity biomechanics across different mouse positions in a computer workstation. Ergonomics 2006;49(14):1456-69. PubMed PMID: 17028089. Epub 2006/10/10. eng.

[33] Asundi K, Odell D, Luce A, Dennerlein JT. Changes in posture through the use of simple inclines with notebook computers placed on a standard desk. Appl Ergon 2011. PubMed PMID: 21774912. Epub 2011/07/22. Eng.

[34] Rempel D, Barr A, Brafman D, Young E. The effect of six keyboard designs on wrist and forearm postures. Appl Ergon 2007;38(3):293-8. PubMed PMID: 16806042.

[35] Armbruster C, Sutter C, Ziefle M. Notebook input devices put to the age test: The usability of trackpoint and touchpad for middle-aged adults. Ergonomics 2007;50(3):426-45. PubMed PMID: 17536778. Epub 2007/06/01. eng.

[36] Sutter C, Ziefle M. Interacting with notebook input devices: An analysis of motor performance and users' expertise. Hum 
Factors 2005;47(1):169-87. PubMed PMID: 15960095. Epub 2005/06/18. eng.

[37] Jacobs K, Foley G, Punnett L, Hall V, Gore R, Brownson E, et al. University students' notebook computer use: Lessons learned using e-diaries to report musculoskeletal discomfort. Ergonomics 2011;54(2):206-19. PubMed PMID: 21294018. Epub 2011/02/05. eng.

[38] Jacobs K, Kaldenberg J, Markowitz J, Wuest E, Hellman M, Umez-Eronini A, et al. An ergonomics training program for student notebook computer users: Preliminary outcomes of a six-year cohort study. Work 2013;44(2):221-30. PubMed PMID: 23324722. Epub 2013/01/18. eng.

[39] Gustafsson E, Johnson PW, Lindegard A, Hagberg M. Technique, muscle activity and kinematic differences in young adults texting on mobile phones. Ergonomics 2011;54(5):47787. PubMed PMID: 21547792. Epub 2011/05/07. eng.

[40] Gustafsson E, Johnson PW, Hagberg M. Thumb postures and physical loads during mobile phone use - a comparison of young adults with and without musculoskeletal symptoms. J Electromyogr Kinesiol 2010;20(1):127-35. PubMed PMID: 19138862. Epub 2009/01/14. eng.

[41] Jonsson P, Johnson PW, Hagberg M. Accuracy and feasibility of using an electrogoniometer for measuring simple thumb movements. Ergonomics 2007;50(5):647-59. PubMed PMID: 17454085. Epub 2007/04/25. eng.

[42] Jonsson P, Johnson PW, Hagberg M, Forsman M. Thumb joint movement and muscular activity during mobile phone texting - A methodological study. J Electromyogr Kinesiol 2011;21(2):363-70. PubMed PMID: 21123082. Epub 2010/12/03. eng.

[43] Trudeau MB, Catalano PJ, Jindrich DL, Dennerlein JT. Tablet keyboard configuration affects performance, discomfort and task difficulty for thumb typing in a two-handed grip. PLoS One 2013;8(6):e67525. PubMed PMID: 23840730. Pubmed Central PMCID: 3694062. Epub 2013/07/11. Eng.

[44] Trudeau MB, Udtamadilok T, Karlson AK, Dennerlein JT. Thumb motor performance varies by movement orientation, direction, and device size during single-handed mobile phone use. Hum Factors 2012;54(1):52-9. PubMed PMID: 22409102. Epub 2012/03/14. eng.
[45] Trudeau MB, Young JG, Jindrich DL, Dennerlein JT. Thumb motor performance varies with thumb and wrist posture during single-handed mobile phone use. J Biomech 2012; 45(14):2349-54. PubMed PMID: 22858316. Epub 2012/ 08/04. eng.

[46] Otten EW, Karn KS, Parsons KS. Defining thumb reach envelopes for handheld devices. Hum Factors 2013;55(1):4860. PubMed PMID: 23516793. Epub 2013/03/23. eng.

[47] Karlson AK, Bederson BB, Contreras-Vidal JL. Understanding onehanded use of mobile devices. In: Lumsden J, editor. Handbook of research on user interface design and evaluation for mobile technology. Hershey, PA: National Research Council of Canada Institute for Information Technology; 2008. pp. 86-101.

[48] Young JG, Trudeau M, Odell D, Marinelli K, Dennerlein JT. Touch-screen tablet user configurations and case-supported tilt affect head and neck flexion angles. Work 2012;41(1):81-91. PubMed PMID: 22246308. Epub 2012/01/17. eng.

[49] Young JG, Trudeau MB, Odell D, Marinelli K, Dennerlein JT. Wrist and shoulder posture and muscle activity during touchscreen tablet use: Effects of usage configuration, tablet type, and interacting hand. Work 2013;45(1):59-71. PubMed PMID: 23531566. Epub 2013/03/28. eng.

[50] Pereira A, Miller T, Huang YM, Odell D, Rempel D. Holding a tablet computer with one hand: Effect of tablet design features on biomechanics and subjective usability among users with small hands. Ergonomics 2013;56(9):1363-75. PubMed PMID: 23909815. Epub 2013/08/06. Eng.

[51] Kim JH, Aulck L, Bartha MC, Harper CA, Johnson PW. Differences in typing forces, muscle activity, comfort, and typing performance among virtual, notebook, and desktop keyboards. Appl Ergon 2014;45(6):1406-13. PubMed PMID: 24856862.

[52] Szeto GP, Lee R. An ergonomic evaluation comparing desktop, notebook, and subnotebook computers. Arch Phys Med Rehabil 2002;83(4):527-32. PubMed PMID: 11932856. Epub 2002/04/05. eng. 